\title{
Los últimos libros de Ramón Fernández Durán: legado político de una mirada lúcida para transformar el mundo del siglo $\mathbf{X X I}^{*}$
}

Marta Soler Montiel ${ }^{* *}$

\section{Resumen}

El Antropoceno y la Quiebra del capitalismo global son los dos últimos libros de Ramón Fernández Durán publicados por la editorial Virus en el primer trimestre de 2011 poco antes de la muerte del autor. Por tanto, reseñar estos libros implica inevitablemente revisitar la totalidad de la obra y el pensamiento de Ramón Fernández Durán. Su mirada al mundo actual es una mirada compleja en la que siempre están presentes cuatro dimensiones: la biofísica, la económicafinanciera, la política y la social, cultural y humana. El trabajo de Ramón Fernández Durán se centra en el análisis de la realidad material o segunda piel que es el sistema urbano-agro-industrial con una especial atención a lo urbano, la metrópolis, en el contexto económico actual de la globalización financiera. A través de este análisis de la realidad material y biofísica disecciona y visibiliza los mecanismo de dominación que se articulan desde lo económico-financiero, lo políticamente institucionalizado y lo simbólico (esa tercer piel de la tecnoesfera) para finalmente mostrar las consecuencias ambientales, sobre la primera piel, y sociales, sobre las personas que padecen la violencia del capitalismo. Un pensamiento, una obra y una vida siempre orientadas a la transformación emancipatoria de la realidad.

\section{Palabras clave}

Metrópolis; Globalización; Globalización financiera; Antropoceno; crisis; Sostenibilidad; Transformación social

\section{Abstract: The last books of Ramón Fernández Durán: the political legacy of a clear approach to transform the world of the 21st century}

El antropoceno (The anthropocene) and La quiebra del capitalismo global (Breakdown of global capitalism) were the last two books by Ramón Fernández Durán published by Virus in the first quarter of 2011, shortly before his death. Therefore, reviewing these books necessarily implies revisiting the complete works and ideas of Ramón Fernández Durán. His approach to the current world is complex and always considers four dimensions: the biophysical dimension, the economic-financial dimension, the political and social dimension, and the cultural and human dimension. The work of Ramón Fernández Durán focused on analyzing the material reality or second skin that is the urban-agro-industrial system with a special focus on the urban sphere, the metropolis, in the current economic context of financial globalization. Through this analysis of the material and biophysical reality, he dissected and showed the mechanisms of domination exerted by economic-financial, politically institutionalized and symbolic spheres (the third skin of the technosphere) and finally exposed the environmental and social consequences on the first skin, that is, the people who suffer the violence of capitalism. His ideas, work and life were always aimed at transforming reality through emancipation.

\section{Key words}

Metropolis; Globalization; Financial globalization; Anthropocene; Crisis; Sustainability; Social transformation.

Recibido: 16/09/2011; aceptado definitivamente: 21/09/2011

* El Antropoceno La expansión del capitalismo global choca con la biosfera febrero 2011, Editorial Virus

La Quiebra del capitalismo global: 2000-2030 Preparándonos para el comienzo del colapso de la Civilización Industrial El inicio del fin de la energía fósil: una ruptura histórica total marzo 2011, Editorial Virus.

** Dpto. Economía Aplicada II, Universidad de Sevilla. Ecologistas en Acción. E-mail: msoler@us.es. 
Comenzar es difícil

pero vamos dando los pasos por un futuro, que los hijos puedan celebrar somos el viento, que baila y que canta si estamos juntos, somos huracán Amparanoia

Lo efimero no es lo opuesto a lo eterno Lo opuesto a lo eterno es lo olvidado John Berger

Quiero ver todo lo que va a venir (...) Quiero estar en la calle

Dentro del laberinto

Amaestrando al hambre y a la angustia Sin ovillo de bilo y con los ojos abiertos Jorge Riechmann

Esto es real: las viñas, el ciclista, La caja de tomates, el gato negro y pardo al que no dejan entrar en la casa. Y el esfuerzo de éste, de aquélla, de este otro por vivir una vida sin servidumbre, hasta donde se pueda limpia, libre de autoengaño y que no de la espalda al misterio de las cosas Jorge Riechmann

Ramón Fernández Durán murió la mañana del martes 10 de mayo de 2011. Su muerte ha sido también, como todo lo suyo, un acto político desde el corazón, en sus propias palabras "el último acto de libertad y dignidad que debe tener una persona". Aquejado de un cáncer de garganta que se reprodujo tras varios años, a principios de 2011 decidió abandonar el tratamiento de quimioterapia, como nos contó en su carta de despedida:

"quiero vivir el tiempo que me quede, mejor dicho el que yo decida, con la mayor calidad de vida posible, dentro de un orden, para poder hacer las cosas que quiero. Entre ellas terminar algunos temas pendientes, pero también poder disfrutar de la vida" (http://www.rebelion.org).
Entre esos temas pendientes estaban sus dos últimos libros publicados este mismo año antes de su muerte por la Editorial Virus.

Para quienes hemos tenido la enorme suerte de conocer personalmente a Ramón, hablar de sus escritos es hablar con y de él, de lo vivido y aprendido con y de él, que es tanto. Especialmente para personas como yo, nacidas en torno a 1970, cuya mirada adulta del mundo -y nuestra manera de transitar por él- ha sido conformada por sus charlas, libros, conversaciones, cuidados y muy especialmente por su cariñosa, honesta y coherente forma de estar y de vivir.

La vida y el trabajo de Ramón, todos sus libros, artículos, charlas y reflexiones, pero también su forma de relacionarse con sus mundos, el cuidado de sus vínculos, nos ayudan a responder a dos preguntas vitales fundamentales: ¿qué está pasando? y ¿qué podemos hacer? Qué podemos hacer, tanto en lo cotidiano y doméstico como en lo colectivo y público, para avanzar hacia un mundo más justo, más libre, más cariñoso, más habitable, en paz con las personas y con la naturaleza. Qué podemos hacer para vivir una vida con sentido.

El Antropoceno constituye una magnífica síntesis explicativa del estado actual del mundo al comienzo del siglo XXI, una lúcida respuesta crítica a la pregunta ¿qué está pasando? poniendo el énfasis en el porqué. Si alguno de mis alumnos o alumnas me pidiera un texto corto que explicara que está sucediendo en la actualidad y le diera claves para comprender las causas y procesos subyacentes, les entregaría sin dudarlo un ejemplar de este libro, perfecto manual actualizado de Ecología Política. En él, Ramón nos explica que el mundo ha entrado en una nueva era histórica en la que la incidencia humana sobre la Tierra es ahora la principal fuerza geomorfológica con impactos ambientales determinantes. Tras este cambio histórico se esconde la dinámica del sistema urbano-agro- 
industrial guiado por la lógica del crecimiento y la acumulación. El análisis crítico de esta segunda piel -espacio construido o alterado por la especie humana- es uno de los objetivos fundamentales del trabajo de Ramón así como la visibilización de los impactos sobre la primera piel, la naturaleza.

La quiebra del capitalismo global es, por otra parte, una mirada política hacia el futuro inmediato consecuencia del diagnóstico crítico del presente. En este texto ${ }^{1}$ se trazan los principales ejes de cambio hacia un escenario -que muchos encontrarán pesimista- para las próximas décadas, en caso de mantenerse las actuales tendencias dominantes. Pero el lector y la lectora atenta encontrarán también en este libro, pistas lúcidas y vitalistas sobre ¿qué podemos hacer? a través de una política nocturna o de éxodo que ya se está desarrollando en

"multitud de microprocesos sociales y alternativas de carácter local, que han decidido no esperar y empezar a construir ya otro orden económico, social y ambiental, a pequeña escala, en contra de la lógica del capital, relocalizando la producción y el consumo y creando nuevas estructuras comunitarias. Eutopías que cristalizan utopías en lugares concretos, sobre la base también de la simplicidad voluntaria y la sobriedad alegre" para de la mano de "estrategias de transformación, conservación ambiental y reparación ecológica local [...] transformarse personal y colectivamente, organizarse, enraizarse, crear mundos propios más justos, autosuficientes y sustentables, y ganar fuerzas" ( $p$. 106).

La formación académica como urbanista de Ramón Fernández Durán quizás conformó su mirada biofísica del mundo a través del intento de comprender el territorio, y especialmente el urbano, donde confluye lo técnico-material, lo económico-

\footnotetext{
1 Se trata de un avance de un libro más amplio e inacabado sobre el análisis del siglo $\mathrm{XX}$ y del comienzo del siglo XXI, así como sobre por dónde avanzar y cómo en la transformación hacia un mundo más habitable. De la mano de Luis González esperamos recibir en el futuro esta obra, que será ya póstuma,
} de Ramón Fernández Durán. monetario, lo político y lo sociocultural en el mundo actual, sobre todo en Occidente. En sus trabajos hay una especial atención a la comprensión holista de la metrópolis mostrando sus conexiones con lo industrial y, lo que es menos frecuente, con lo rural y agrario, al analizar la organización material de la actividad humana que se desarrolla crecientemente en lo urbano. Este análisis está especialmente desarrollado en su magnífico e imprescindible libro La explosión del desorden. La metrópolis como espacio de la crisis global (1993, Editorial Fundamento).

En todos los trabajos de Ramón el análisis complejo de la realidad material, de esa segunda piel que es el sistema urbano-agro-industrial y sus impactos sobre la primera piel, así como sus relaciones con la tercera piel inmaterial de la infoesfera, aglutina distintas dimensiones que aparecen continúa y simultáneamente, además de con el mismo rango de importancia, lo que es más difícil de hilar. En El Antropoceno se evidencian los niveles insostenibles tanto de extracción de materiales y energía de la naturaleza como de generación de residuos y contaminación. En La quiebra del capitalismo global nos recuerda que

"de aquí a poco quedará meridianamente claro que no podremos vivir ni sobrevivir sin tener en cuenta que no sólo somos interdependientes, sino también eco-dependientes" (p. 98).

En estos dos últimos libros, se pone de manifiesto la situación límite y contradictoria de la vida en nuestro planeta entre el agotamiento de los recursos básicos para la misma (agua, aire, biodiversidad, tierra fértil...) y para el crecimiento y la acumulación económica (petróleo y otros combustibles fósiles, minerales...) y la degradación ambiental resultante, especialmente, pero no exclusivamente, el cambio climático, así como la dolorosa conflictividad social que surge del desorden cuando se carece de proyecto de futuro. En ambos textos, se visibilizan de forma magistralmente clara y 
sintética los procesos causales y explicativos de dicha realidad hilando distintas dimensiones.

La dimensión ambiental de su análisis es el resultado de una mirada biofísica de la realidad en continúo diálogo con la mirada de la Economía Ecológica y de la Ecología Política. La comprensión del mundo de Ramón nace, por una parte, del humilde respeto a la jerarquía de sistemas ${ }^{2}$ que nos enseña que lo económico-monetario es un subsistema de lo social que a su vez es un subsistema subordinado y dependiente del sistema superior que es la biosfera en el que se desenvuelve la vida, también la humana. Pero esta comprensión ecológica y ecologista del mundo surge también de su espíritu autónomo que le lleva a mirar críticamente los mecanismos de dominación que generan dependencias y subordinaciones, como la explotación gratuita de la naturaleza y su íntima unión con la opresión de las personas, sin la que el actual sistema urbano-agro-industrial no podría subsistir. Un énfasis especial recibe la voracidad energética de una economía y un modo de vida basados en el despilfarro, es decir, en la producción y el consumo en masa, en espacios urbanos crecientemente concentrados y dependientes de la hipermovilidad a través de vehículos motorizados privados. Esta dependencia energética de los combustibles fósiles y sobre todo del petróleo es objeto fundamental de análisis en todos los libros de Ramón aunque especialmente en El crepúsculo de la era trágica del petróleo. Pico del oro negro y colapso financiero (y ecológico) mundial (2008, Editorial Virus).

La dimensión económico-financiera como expresión dominante del poder conformador del mundo actual es otro eje de análisis transversal de su mi-

\footnotetext{
2 La lectura de La explosión del desorden ha marcado y sigue marcando a lectores y lectoras, especialmente jóvenes con inquietud crítica y política buscando comprender el mundo en el que viven y encontrar sentido a su transitar por la vida, como fue mi caso siendo alumna de doctorado en la Universidad de Sevilla a mediados de la década de 1990 y posteriormente en Ecologistas en Acción, colectivo en el que sigo participando hasta la actualidad.
}

rada y el objeto prioritario de análisis en sus libros Capitalismo (financiero) global y guerra permanente. El dólar, Wall Street y la guerra contra Irak (2003, Editorial Virus) y El tsunami urbanizador español y mundial. Sobre las causas y repercusiones devastadoras, y la necesidad preparase para el previsible estallido de la burbuja inmobiliaria (2006, Editorial Virus). Especialmente notable fue la anticipación del estallido de la burbuja inmobiliaria en el Estado español en El tsunami urbanizador, así como el análisis de los mecanismos perversos que la impulsaron y de los dolorosos resultados para la sociedad y la naturaleza. En su último libro, La quiebra del capitalismo global, Ramón nos recuerda con total vigencia a la luz de la reciente reforma de la Constitución del Estado español que

"el eslabón más frágil del actual Capitalismo Global es su dimensión financiera, aunque todavía nos parezca la más potente, y en aras de la cual hay que sacrificar cualquier cosa. De hecho, los principales Estados centrales han dedicado cantidades ingentes de dinero, obtenidos a través de la emisión de deuda a través de mecanismos monetarios, a salvar sus sistemas financieros y a contener como fuera la depreciación de activos de todo tipo (bursátiles, inmobiliarios, financieros, etc.). Un verdadero Golpe de Estado global de las finanzas. $Y$ lo han logrado, momentáneamente, a costa casi de suicidarse en el intento, y sobre todo de arrasar con el Estado Social, o los restos del mismo, para pagar al capital financiero unos intereses desorbitados por las deudas que le prestaba. Increíble" ( $p$. 58).

El análisis de la realidad que hace Ramón Fernández Durán incorpora siempre una dimensión política que disecciona el poder y los mecanismos de dominación actuales donde se hace explícita una denuncia de la violencia del capitalismo, entre ellos los mecanismos, lógicas y estrategias del poder político institucionalizado. El papel activo en la construcción de la globalización capitalista de los organismos internacionales como el Banco 
Mundial, el Fondo Monetario Internacional o la Organización Mundial del Comercio son objeto constante de análisis en su obra ${ }^{3}$. Aunque su crítica al poder del Estado y sus servilismos hacia los intereses económicos de las élites privilegiadas la encontramos en todos sus escritos, una especial atención le dedica a la Unión Europea en dos libros Contra la Europa del capital y la globalización económica (1996, Editorial Talasa) y La compleja construcción de la Europa superpotencia. Una aportación al debate sobre el futuro del Proyecto Europeo y las resistencias que suscita (2005, Editorial Virus). En el más reciente El Estado y la conflictividad político-social en el siglo XX (2010, Editorial Virus) encontramos un crítico análisis histórico del aparato estatal en el siglo XX seguido de la presentación también en clave histórica de las expresiones sociales antagonistas. Queda patente que el Estado no es un agente al servicio de la sociedad del que se pueda esperar avances emancipatorios, todo lo contrario se muestra como institución represora al servicio del (des)orden establecido.

La mirada política de Ramón es una mirada hacia el poder y sus consecuencias para las personas y la naturaleza en la que la dimensión política de sus análisis se articula siempre con la dimensión social y cultural excepcionalmente humana. En su libro Tercera piel. Sociedad de la imagen y la conquista del alma (2010, Editorial Virus) analiza los mecanismos de poder de lo simbólico a través de la creación de mitos y el control de los valores y las subjetividades apelando a las emociones que hacen los medios de comunicación y muy espe-

\footnotetext{
3 Además de lucha política, como ponen de manifiesto su participación activa y señalada en la campaña 50 años bastan. Las otras voces del planeta, centrada en la denuncia de las llamadas instituciones de Bretton Woods, de la que surge el libro coordinado por Antonio Estevan El libro del Foro Alternativo. Las otras voces del planeta (1995, Editorial Talasa). Posteriormente participó activamente en la campaña Contra la Europa del capital y en el movimiento antiglobalización articulado localmente tras las movilizaciones de Seattle en diciembre de 1999.
}

cialmente la televisión. Frente a los dioses de la (post)modernidad, como el progreso, el desarrollo y especialmente el desarrollo sostenible, apunta en La quiebra del capitalismo global: 2000-2030 que

"es un deber inexcusable que creemos nuestro propios Dioses [...] nuestros nuevos relatos del mundo [...]. Y habrá que realizar todo ello a través de múltiples formas, desde relatos escritos y educativos a nuevos mensajes musicales y artísticos [...]. Y lo debemos hacer para interpelar a las generaciones actuales ante la Catástrofe, para colocarlas ante el espejo de su (nuestra) responsabilidad, para cambiar sus (nuestras) mentes y corazones, y para que tomen (tomemos) el futuro en sus (nuestras) propias manos, con todas las enormes dificultades que ello implica, transformando nuestro actual Yo competitivo en un nuevo Yo cooperativo. Pues solo la verdad es revolucionaria y puede llegar a cambiar el curso de la Historia de forma liberadora" (p. 97).

El análisis complejo de las desigualdades sociales muestra múltiples mecanismos de dominación y exclusión que implican múltiples agentes potenciales de resistencia y cambio. Ramón dirige siempre su mirada hacia el sufrimiento de quienes padecen la violencia que genera el poder. $Y$ no elude nunca apuntar las (nuestras) responsabilidades en un mundo construido social y políticamente al servicio de los privilegios de una minoría -o no tales minorías cuando se trata de los y las cómplices complacientes anestesiados vía consumo-. Su trabajo es una continua e incansable labor para visibilizar a los y las invisibles ${ }^{4}$, denunciando la violencia del capitalismo y a la vez mostrando las resistencias y todo lo que tenemos que aprender de las personas y luchas de espacios, territorios y pueblos ignora-

\footnotetext{
${ }^{4}$ Como apunta Boaventura de Sousa Santos, practicando una sociología de las ausencias para expandir el presente transformando las ausencias en presencias, practicando también una sociología de las emergencias que permita contraer el futuro sustituyendo "el vacío [...] por un futuro de posibilidades plurales y concretas" (El milenio huérfano. Ensayos para una nueva cultura política. Editorial Trotta, 2005, p. 167).
} 
dos y despreciados por la cosmovisión de la (post)modernidad occidental: los y las habitantes del Sur, de las Periferias -también las del Norte-, de lo rural y campesino, de los pueblos indígenas... los y las habitantes de los márgenes.

Y no olvida nunca -no nos olvida nunca- a las mujeres y ese mecanismo de dominación, el patriarcado, especialmente perverso por lo que tiene de universal y de negado, reclamando incesantemente la feminización de nuestro mundo. En La explosión del desorden afirma contundentemente que

"el cuestionamiento de los valores masculinos es un elemento clave del cuestionamiento en general de la estructura de poder del actual modelo pues lo masculino ha sido siempre y es un instrumento de penetración del poder en lo social y una forma de consolidar los mecanismos de dominio y opresión. En esa vía, tanto la feminización de los sujetos sociales, es decir, la introducción de valores femeninos que se enfrenten al contenido patriarcal de la ideología masculina dominante, como la lucha contra la histórica división sexual de los espacios funcional con los intereses del poder, y que se afianza en la sociedad actual-, creando al mismo tiempo espacios intermedios de convivencia y producción de carácter comunitario, que permitan ir eclipsando la dicotomía público-privado, se piensa que es determinante para reforzar la autonomía de lo social" (p. 357).

En La quiebra del capitalismo global nos vuelve a alertar de la crisis de los cuidados y del "conflicto creciente entre la lógica del capital y la lógica de la vida" (p. 43) y nos insta a

"ir caminando hacia el fin de la Guerra y la Violencia como forma determinante de las actuales relaciones intraespecie, y elementos claves de la fuerza del patriarcado y de la desigualdad social existente. Unas relaciones de las que se benefician prioritariamente unas minorías sociales mundiales [...], unas considerables clases medias [...], pero también en mayor o menor grado la mitad masculina del Homo sapiens a escala global, que ejerce no sólo una mayor o menor explotación, sino en muchos casos la violencia contra la otra mitad: las mujeres del mundo" (p. 113).

El análisis del mundo que nos toca vivir que hace Ramón es siempre análisis para la acción, para transformar nuestras vidas en lo personal y en lo colectivo, tanto en el espacio público como en el privado, como expresiones de autonomía que superan los mecanismos de dominación creando nuevos vínculos, nuevos espacios y proyectos vitales que construyan nuevas materialidades, otra segunda piel en armonía con la primera piel impulsada por una nueva tercera piel. Esta mirada, para algunos pesimista, es su transitar por la vida con los ojos abiertos, porque solo podemos caminar y construir alternativas reales desde donde estamos realmente, mirando cruda y abiertamente lo que hay, libres de autoengaño, haciéndonos cargo del daño causado. Las últimas décadas han sido un tiempo perdido precioso y ahora estamos en un lugar más complicado para la tarea de desandar lo andado:

"y ahora que el futuro ha estallado en el presente, nos vemos obligados a mirar hacia atrás, hacia el pasado, para poder avanzar a tientas hacia un futuro muy complejo y descorazonador" (La quiebra del capitalismo global, 2011, p. 92).

Ramón Fernández Durán abandonó en la década de 1980 su plaza de funcionario para, desde una posición mucho más precaria, concentrarse en su labor política de análisis, reflexión, escritura, comunicación y acción. Repartió su tiempo entre las aulas de la Academia y los espacios sociales alternativos, siempre desde Ecologistas en Acción. Impartió clases y charlas en múltiples cursos y jornadas en muy distintas Universidades a la vez que habló y compartió reflexiones en los foros políticos alternativos, muy especialmente en los espacios okupados, autónomos y autogestionados. En todos los espacios mantuvo siempre el mismo discurso, con una coherencia impresionante. Esa humilde, digna, fuerte, clara y siempre cariñosa forma de decir es toda una lección humana de estar en el mundo. Su casa estuvo siempre abierta 
para los y las amigas y él disponible para atender cariñosa y cuidadosamente a todas las personas de sus múltiples mundos entre los que tejió un hilo armonioso. Parafraseando el poema de Miquel Martí i Pol que canta Kiko Veneno, Ramón nunca pidió mucho y "vivió sin cambiar la voz, sin muletas, sin rayas y sin pedir permiso". La forma de estar y de vivir de Ramón Fernández Durán ha anticipado ese futuro que ansiamos siendo fiel a la propuesta de Julio Cortázar en el Libro de Manuel: "más que nunca creo que la lucha $[. .$.$] debe en-$ frentar el horror cotidiano con la única actitud que un día le dará la victoria: cuidando preciosamente, celosamente, la capacidad de vivir tal como la queremos para ese futuro, con todo lo que supone de amor, de juego y de alegría [...] es el signo afirmativo frente a la escalada del desprecio y del espanto, y esa afirmación tiene que ser lo más solar, lo más vital del hombre: su sed erótica y lúdica, su liberación de los tabúes, su reclamo de una dignidad compartida en una tierra ya libre de ese horizonte diario de colmillos y de dólares".

Gracias Ramón, por todo, que es mucho.

\section{Cita del artículo:}

SOLER MONTIEL, Marta. Los últimos libros de Ramón Fernández Durán: legado político de una mirada lúcida para transformar el mundo del siglo XXI. Hábitat y Sociedad, 2011, n², p. 197-203.

<www.habitatysociedad.us.es>.

http://dx.doi.org/10.12795/HabitatySociedad.2011.i2.11 